\title{
Endoscopic resection with the cap technique of a carcinoid tumor in the duodenal bulb
}

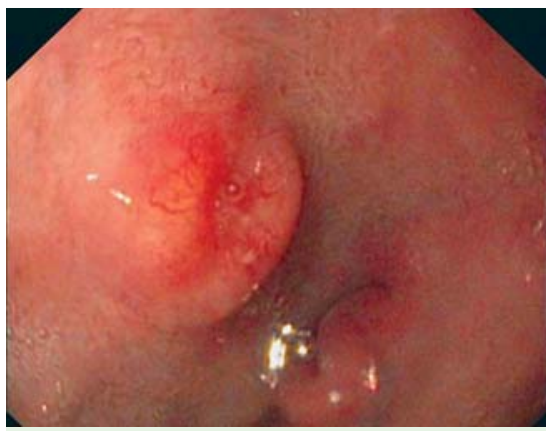

Fig. 1 Upper gastrointestinal tract endoscopy showed a round lesion covered by normal mucosa with a central depression, located in the posterior duodenal bulb.

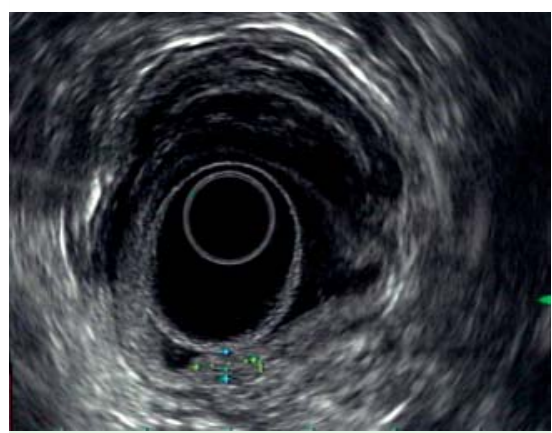

Fig. 2 Endoscopic ultrasound view of the lesion, $10 \times 5 \mathrm{~mm}$ in size, confined to the submucosal layer of the duodenal bulb.

Well-differentiated neuroendocrine tumors, also called carcinoid tumors, in the duodenum are rare. The therapeutic approach is highly dependent on both tumor size and depth of invasion; for tumors smaller than $1.0 \mathrm{~cm}$ and without penetration of the muscularis propria, endoscopic resection is considered as the method of choice [1].

A 65-year-old woman with a histologically proven neuroendocrine tumor in the duodenal bulb was referred for further evaluation. Upper gastrointestinal endoscopy ( $\bullet$ Fig. $\mathbf{1}$ ) revealed a single, slightly elevated, round lesion that was covered by normal mucosa and had a central depression. Endoscopic ultrasonography ( $\bullet$ Fig. 2) revealed a $10-\mathrm{mm}$ lesion without penetration into the muscularis propria. There were no signs of regional lymph node metastasis.

Somatostatin receptor scintigraphy was also negative for metastatic spread. Therefore, endoscopic en-bloc resection of the

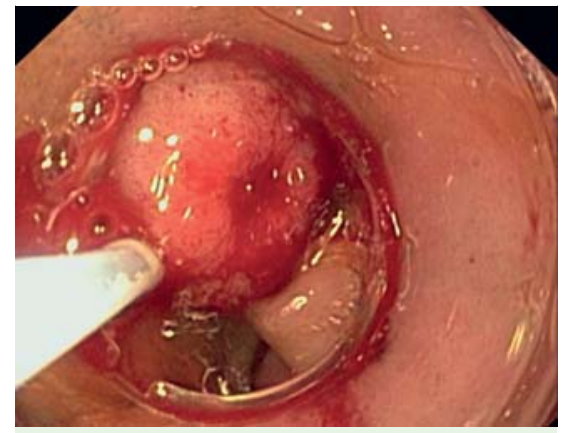

Fig. 3 Endoscopic resection of the carcinoid tumor, using the cap technique.

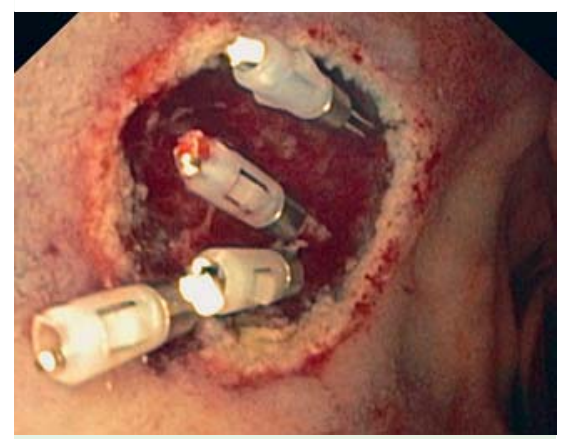

Fig. 4 Bleeding controlled with an epinephrine injection and placement of four metal clips.

lesion using the cap technique ( Fig. 3 ) was carried out. After the resection, an arterial bleeding was noted, which was successfully controlled with a hypertonic saline and epinephrine injection and placement of four metal clips ( $\bullet$ Fig. 4).

Macroscopically, the tumor was completely removed ( $\bullet$ Fig. 5), and this was confirmed histologically ( $\bullet$ Fig. 6 ). Immunohistochemical staining was strongly positive for synaptophysin and chromogranin. Recovery was uneventful and the patient was discharged the following day after a second-look endoscopy.

The present case illustrates that endoscopic en-bloc resection with the cap technique is an effective method for the curative treatment of carcinoid tumors in the narrow area of the duodenal bulb. Laparoscopic techniques may be considered as an alternative only in cases where endoscopy is deemed unsuitable [2].

Endoscopy_UCTN_Code_TTT_1AO_2AG

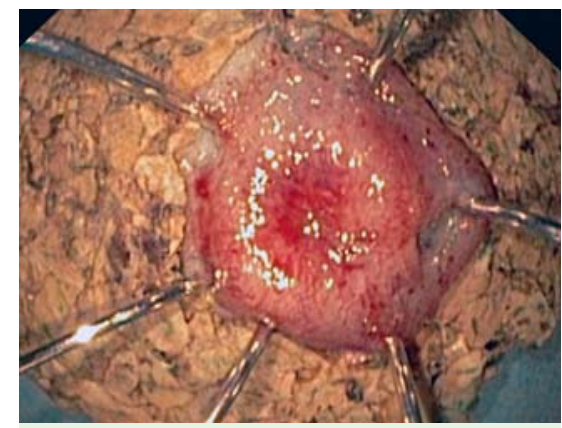

Fig. 5 Macroscopic view of the resected carcinoid.

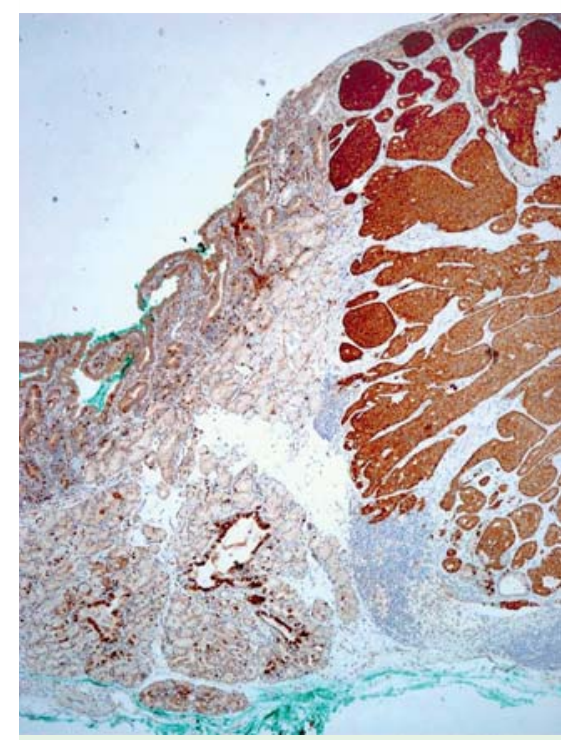

Fig. 6 Well-differentiated, synaptophysin-positive neuroendocrine tumor of the duodenum with tumor-free margins (magnification $\times 40$ ).

\section{S. Karagiannis ${ }^{1}$, K. Eshagzaiy ${ }^{1}$, \\ C. Duecker ${ }^{1}$, B. Feyerabend ${ }^{2}$, \\ E. Mozdzanowski ${ }^{3}$, S. Faiss ${ }^{1}$}

1 Department of Gastroenterology and Hepatology, Asklepios Klinik Barmbek, Hamburg, Germany

2 Hanse Histologikum, Hamburg, Germany

Praxis Drs Mozdzanowski, Hamburg, Germany

* Dr. S. Karagiannis is currently working at the Department of Gastroenterology and Hepatology, Asklepios Klinik Barmbek, Hamburg, Germany, supported by a grant of the Hellenic Society of Gastroenterology. 
References

1 Dalenbäck J, Havel G. Local endoscopic removal of duodenal carcinoid tumors. Endoscopy 2004; 36: $651-655$

2 Bowers SP, Smith CD. Laparoscopic resection of posterior duodenal bulb carcinoid tumor. Am Surg 2003; 69: $792-795$
Bibliography

DOI 10.1055/s-0029-1215123

Endoscopy 2009; 41: E288 -E289

(c) Georg Thieme Verlag KG Stuttgart · New York . ISSN 0013-726X

\section{Corresponding author}

S. Karagiannis, MD, PhD

Department of Gastroenterology and Hepatology Asklepios Klinik Barmbek

Hamburg

Germany

Fax: +49-40-1818823809

s.karagiannis@asklepios.com 